\title{
Valoración de los métodos de exploración de la función tubárica
}

\author{
Doctor Ricardo Rueda González \\ Jefe de Clínica Ginecológica. Hospital San Juan de Dios, de Bogotá. Adjunto \\ de la Consulta de Ginecología. Hospital San Jcsé, de Bogctá.
}

Uno de los pasos fundamentales en el estudio de la infertilidad femenina es el estudio del factor tubárico que presenta en nuestro medio una incidencia que llega ai 35\%, dada la gran fre. cuencia de las infecciones puerperal y blenorrágica.

Ahora bien: el estudio del factor tubárico no debe reducirse simplemente a establecer por un medio cualquiera si existe o no permeabilidad, que si bien es una condición fundamental en la trompa, no representa por sí sola sino una función pasiva, que comparte su finalidad con las que podemos denominar funcio. ries activas, como son la captación, la conducción y la nutrición.

Estas funciones activas de la trompa siempre se deberán expiorar en el estudio de la fisiología tubárica, y por ello considera. mos erróneo el empleo del término "pruebas de permeabilidad tubárica" cuando se trata del estudio del factor tubárico, ya que éste solamente enfoca el problema por la condición anatómica, despreciando la parte funcionai. Creemos, por consiguiente. que hay necesidad c.e cambiarlo por el de "pruebas de función tubárica". que engloba tanto la permeabilidad o función pasiva a la concucción, captación y nutrición o funciones activas.

Después de esta breve introducción queremos intentar hacer algunas consideraciones a los métodos usuales de exploración tubárica. No entraremos en descripciones compietas de técnica, y solamente nos limitaremos a valorar su utilidad, ventajas y cesventajas.

Insuflación.-Es el sistema indudabiemente más discutido en la actualidad y cuyo número de seguidores creemos va disminuyendo a diario. Es innegable que es bastante práctico y sen- 
cillo de realizar, pues la industria fabrica excelentes aparatos de fácil manejo y que eliminan los peligros al máximo. Pero sus re_ sultados no siempre se encuentran de acuerdo con la realidad.

La insuflación de las trompas podemos cataiogarlas como un método de exploración ascendente, dirección que, como es fácil de comprender, contraría por completo los postulados de fisiología tubárica. En efecto, el peristaltismo de ia trompa es descendente el movimiento de las cilias celulares se hace en dirección contraria a la corriente de $\mathrm{CO} 2$ que se insufla, y la dirección que sigue el óvulo es también descendente. Todos estos hechos han sido comprobados experimentalmente desde hace ya largo tiempo.

Pasando ahora al problema concreto de los resultados obtenidos con la insuflación, vemos como el paso del gas informa únicamente sobre su función pasiva o de permeabilïdad.

Las experiencias de Stabile, Caviglia, Bunster y otros, demuestran cómo las oscilaciones obtenidas en los registros quimográficos no son debidas a motilidad tubárica, ya que se presentan también después de salpinguectomías, en las que no se obtura el cuerno uterino o en las perforaciones practicadas en ei músculo uterino previa ligadura de las trompas. Basado en multitud de observaciones de esta naturaleza, Bunster es categórico en afirmar que las oscilaciones manométricas son debidas a variaciones rítmicas del tono del "esfínter cornual".

La escuela de Montevideo, después de concluir sus experien_ cias, presenta al Primer Congreso Mundial de Fertilidad reunido en New York en 1953 unas conclusiones similares que nos permi. timos resumir a continuación:

a) Las oscilaciones obtenidas en la insuflación son independientes de la contracción tubárica;

b) Las oscilaciones ritmicas coinciden con la contracción miometrial;

c) "En la prueba de Rubin se obtiene un histerograma y no un salpingograma", y

d) Los trabajos realizados para el estudio de la contracción tubárica utilizando el test de Rubin, "tienen valor si se pudieran apiicar sus conclusiones a la fisiopatología del miometrio".

Estas observaciones indudablemente revalidan por comple. to el concepto que se tenía de la insuflación útero-tubárica y dan mucho qué pensar si se comparan con aquellos test que se ciñen más estrechamente a los postuiados de fisiología tubárica. 
Pero podemos anotar también que en los estudios de infertilidad no se deben omitir, y creemos que deben ocupar el primer lugar en el orden de exploración de la función tubárica, pues nos informa con más o menos exactitud de la permeabiiidad, que como ya hemos anotado es una condición de trascendencia para que se logre la fecundación.

Histerosalpingografía.-Como de los auxiliares diagnósticos de gran estimación es el estudio radiológico de las trompas, cuyo valor es indiscutible cuando se hace con buena técnica y cuando se le adjudica el valor que merece.

Tiene un aspecto halagador en el estudio de la infertilidad ya que informa con lujo de detalies del estado morfológico del canal cervical, de la cavidad uterina y de la luz de las trompas.

Deseamos en esta ocasión hacer resaltar aigunos puntc's que a más de alejar los peligros que con su empleo se puedan presentar. acercan más a la realidad sus resultados.

En primer lugar ,siempre se debe practicar ia inyección del medio de contraste bajo presión controlada, con lo cual podemos tvitar accidentes tan serios como el estallido de la trompa. Por otra parte, y después de haber realizado muchas histero-saipingografías, creemos, con Palmer, que la adición de algún antibiótico al medio de contraste evita al máximo el accidente de tipo infeccioso. Antes del uso de los antibióticos observamos no po. cas infecciones que compiicaban el probiema desencadenando ına hostilidad tubárica grave que seguramente no existía.

La cualidad del medio de contraste es otro factor que nos ha preocupado. Cuando usamos el Lipiodol (liposoluble), observamos cómo en muchos casois la imagen radioiógica no coincidía con la realidad. Este tipo de contraste se detiene en determinado punto, estableciendo en esta forma el sitio de la obstrucción. Sin ambargo en la exploración de la trompa durante ai acto operatorio el hallazgo era completamente diferente, la obstrucción existía más aliá del lugar indicado por la detención del Lipiodol.

Hemos concluído que la formación de una burbuja de aire por delante del medio de contraste iiposoluble es un hecho evidente y no lo expiicamos por razones de orden mecánico.

Los medios de contraste hidrosoluble nos han dado mejores elementos de juicio, pues no hemos observado con ellos diferen. cia alguna entre la imagen radiológica y el hallazgo quirúrgico.

Ultimamente venimos empleando con tales fines la sal metilgiucamínica del ácido del $\mathrm{N}$, Nadipid n_di (3-amino- 2, 4, 6- 
triyodo-benzoico). (Endografina de la casa Shering), a la que adicionamos 300.000 UI de penicilina.

A esta mezcla de contraste hidrosoluble y penicilina ya empleada por Palmer de ia escuela francesa, y denominada por ellos mezcla viscoso-penicilinada, le encontramos tres cualidades que vale la pena considerar:

a) Evita al máximo el accidente infeccioso;

b) La imagen radioiógica obtenida con ella es bastante níti_ da y la adición del antibiótico parece darle una viscosidad ideal que retarda ligeramente la rápida absorción de los contrastes hidrosolubles, y

c) No se presenta la burbuja de aire y por consiguiente ia imagen sicmpre coincide con la realidad.

Para terminar los comentarios a la histerosalpingografía agregamos que el empleo de la liamada "Ginecografía combina. da" es decir, la histerosalpingografía adicionada de neumoperitóneo, nos está dando resultados cada vez mejores, pues nos informa también de la superficie exterior de útero y de la forma y tamaño de ios ovarios.

Test de Spek.-Es otro de los métodos de exploración de la función tubárica del cual podemos decir lo siguiente:

1) Como el test de Rubin y ei histerosalpingograma, informa. solamente sobre la condición anatómica denominada permeabilidad.

2) Es una prueba ascendente que contraría los postulados de fisiología de la trompa.

3) No localiza el lado del obstácuio, ya que no existe apreciación visual o auditiva alguna que permita afirmarlo. Solamen. te anota si la solución colorante penetró a la cavidad peritoneal a través del tracto genital.

Vemos, pues, que es de mucho menos valor que el test de $\mathrm{Ru}-$ bin y la histerosalpingografía, pero no deja de ser útil en aquellos medios en que no se dispone de buenos recursos.

Hidrotubación.-El método se basa en los mismos principios de la persuflación útero-tubárica, ya que consiste en la introducciór de una substancia a través del orificio cervical con el fin de que al emigrar al tracto genital superior, informe si las trom. pas dan paso o no a ia substancia inyectada. 
La escuela argentina cree haber iniciado las hidrotubacio. nes con control quimográfico, asemejándolas aún más al test de Rubin.

Nosotros no estamos aún en posibilidades de hacer comentarios al sistema, pero creemos que se pueda decir algo parecido a lo anotado a la insuflación.

Lo hemos empleado con fines terapéuticos en casos de fimosis del pabellón, inyectando bajo presión controlada soluciones de penicilina_estreptomicina y suministrando como complemento antiflogísticos (Cortisona o Butazolidina) y diatermia.

Los resultados han sido en ocasiones satisfactorios, pero es_ peramos más observaciones para poder comunicar aigo de valor al respecto.

Deseamos también ensayarlo como coadyuvante en el tratamiento de la T. B. C genital (soluciones de estreptomicina) en mayor escala. Desafortunadamente los dos casos en que lo iniciamos ios perdimos de vista antes de controles, pero creemos po. der reportar resultados en posteriores publicaciones.

Test de Hinselman o prueba de lazul de metileno.-Hinselman inyecta soluciones de azul de metieno a través del orificio cervical, para reconocerlas luego en ei fondo de saco posterior mediante punción de éste.

Es por consiguiente una prueba ascendente de alguna utili_ dad para investigar ia permeabilidad tubárica y a la que podemos también hacer algunas criticas.

En primer lugar una prueba positiva no afirma que ambas trompas están permeables. El azul de metileno puede llegar ai Douglas a través de una de ellas, estando la otra obstruída. Por otra parte, cuando ei "factor peritoneal" es muy intenso, es decir, cuando existen grandes adherencias que llegan a bloquear por completo el fondo de saco posterior, estado relativamente frecuente como secuela de infecciones pélvicas, ei azul de meti. leno se difunde en la parte superior del peritóneo pélvico sin llegar a depositarse en un sitio que esté al alcance de ia punción, dando en esta forma pruebas falsas negativas.

Pruebas descendentes.-Antes de entrar a comentar estas pruebas, creemos importante exponer algunos conceptos de fisiología.

En primer término podemos decir que "trompa normal" no es solamente aquella que permite el paso dei gas, medio de con- 
traste u otra substancia, sino aquella que además de ser permea_ bie es capaz de captar, conducir y nutrir el óvulo liberado por el c vario.

Los conceptos más recientes nos explican que las contrac_ ciones de los ligamentos tubo-ováricos, los movimientos de las ?imbrias y cilias, junto con los desplazamientos de las vísceras vecinas, son factores esenciales para que se cumplan a cabalidad las funciones de captación y conducción, de modo que es necesario un buen peristaltismo y la presencia de un endosalpinx sano y, claro está, la permeabilidad para cataiogar una trompa como sana.

Estas funciones periódicas de la trompa han podido ser ob_ servadas por Decker mediante la culdoscopia. Este autor ha visto con su ingenioso aparato trompas permeables que asientan procesos patológicos tales como perisalpingitis con adherencias, inmoviiización de las fimbrias, endomatriosis, TBC anexo-peritoneal y salpingitis istmica nudosa.

En las mencionadas entidades, lo repetimos, se han obtenido muchas veces pruebas de permeabilidad tubárica satisfacto. rias en contraste con imágenes culdoscópicas anormales y pruebas descendentes negativas, hecho que permiten concluir que ias funciones de captación y conducción están ausentes.

Después die tuboplastias reaiizadas con técnicas impecables y excelentes suturas, es también frecuente observar, y lo anotamos nosotros insistentemente, pruebas de permeabilidad positivas y descendentes negativas.

Por todos los datos anteriormente consignados hemos creído, en acuerdo con algunos autores, que las pruebas descendentes de función tubárica se ajustan más a los postulados de la fisiología tubárica y arrojan datos de inmenso valor en ei estudio de la mujer_problema.

Ahora bien: muchos son los sistemas que se han ideado y que cuadran dentro de la categoria de las pruebas que estamos tratando. En generai todas consisten en la introducción de alguna substancia en la cavidad peritoneal para luego reconocerla en el ta. pón cervical.

Cónil inyecta aceite puro de olivas (prueba del oleotransporte u oieopermeabilidad) y últimamente esferas microscópicas de polimetracrilato de metilo. Peña Regidor usa para el efecto el prontosil rubrum. Decker ha ensayado la introducción de granos de almidón. Pinere, Le Lorier y otros han usado otras subs. 
tancias, tales como el carbón, diversos coiorantes y hasta huevo's de ascaris lumbricoides.

Nosotros, siguiendo a Pendelton y Tomkins de San Francis. ro, hemos practicado inyecciones intra-peritoneales de tinta china a través del fondo de saco posterior para icientificaria luego en el moco cervical.

En la imposibilidad e injustificación de hospitaizar a todas las pacientes les practicamos controles de consultorio a las 24 horas y les recomendamos ún:camente un reposo lo más completo posible.

La inyección ia practicamos en épocas ovuiatorias previa. mente establecidas con curvas de temperatura basal y citología vaginal. Esto por parecernos que en esta época la actividad de la trompa es máxima.

Inyectamos previa anestesia local del fondo de saco posterior y mediante una aguja de raquianestesia 3 c. c. de tinta China, que no está por demás anotar que la envasamos en ampolletas de vidrio y la esterilizamos al autoclave.

Nos hemos inclinado al empleo de la tinta China por varias razones:

1. Su fácil consecución y manejo;

2. Su fácii identificación en el tapón mucoso-cervical;

3. Su carencia de efectos irritantes sobre el peritóneo y trac_ to genital, y

4. Por ser una substancia que aparentemente no se absorbe por el peritóneo.

Los demás elementos mencionados en líneas anteriores no los hemos empleado, pero consideramos que todos son buenos y llenan la finalidad que se persigue.

Estamos esperando completar un buen número de pacientes estudiados con pruebas descendentes para comunicar en próxi. ma oportunidad sus resultados. Pero de todos modos podemos afirmar que son de bastante utilidad y que debemos procurar difundir más su empleo en el estudio del factor tubárico.

$\mathrm{Y}$ como comentario final a estas notas agregamos que ei factor tubárico está frecuentemente asociado a estados peculiares del peritóneo pélvico, que se engloban dentro del término general de "factor peritoneai", para cuyo estudio los métodos ante. riormente tratados presentan una valiosa ayuda. 


\section{BIBLIOGRAFIA}

1. STABIL, AMERICO.- "Interpretación de las oscilaciones manométricas registradas durante la insuflación útero-tubárica". Procedings of the first world congres on Fertility and Sterility. New York. 1953.

2. RODRIGUEZ LOPEZ, MANUEL B.-"Métodos simples para determinar la permeabilidad tubárica”. Ana!es de Ginecología. Año I. Tomo I. Montevideo. 1953.

3. SALOR, R.-"Etude des ocillations registres au cours de linsuffltion kimographique”. Ginecologie Practique. Vol. VII. Número 4. 1956.

4. RUEDA G. RICARDO.- "Algunos comentarios a las pruebas de permeabilidad tubárica". Rev. Col. de Obst. y Gin. Vol. VII. Número 4. Marzo, abril. 1956 .

5. CONIL SERRA, VICTOR.-"Lecciones sobre exploración ginecológica”. I Edic. Ed. Labor. Barcelona. 1955.

6. RUEDA G. RICARDO.-“Contribución al estudio radiológico de las trompas de Falopio”. Rev. Col. de Obst. y Gin. Vol. I. Número 1 Septiembre, octubre. 1955.

7. ARENAS N., BETINOTTI A., MURRAY E.- "Esterilidad conyugal". I Ed. Edit. Bibliográfica Argentina. Buenos Aires. 1956.

8. ENGLE, EARL T.-"Diagnóstico y tratamiento de la esterilidad humana". Edit. Beta. Buenos Aires. 1948.

9. CAMERO C. RODULFO.-Referencia personal.

10. GARRASI, GIUSEPPE.- "Sulle prove della permeabilitá tubarica". Puev. D’Ostetricia e Ginecología práctica. Vol. XXXVIII. Juglio. Número 7, Milano. 1956.

11. DECKER, ALBERT.- “Culdoscopy”. First edition. NB Saunders Company. London. 1952. 